\title{
Aligning Open Badges and Open Credentialing with Open Pedagogical Frameworks to Address the Growing Skills Gap
}

\author{
Leslie B. Eldridge
}

\begin{abstract}
This paper describes how new open pedagogical frameworks can be utilized as powerful strategic tools in addressing the skills gap by aligning industry proficient requirements with educational programs via open badging and open credentialing. Using this strategy and open framework empowers learners to pursue their educational and career development in a highly personalized manner dictated by their interests and the modularity to collect and receive credentials.

This forward progress in an evolutionary open approach creates multiple channels toward employment and educational goals from a broad variety of content providers including traditional educational institutions and industry. Aligning open pedagogical frameworks to educational institutions and industry via open credentials solves several challenges: 1 ) Timely delivery of content and curriculum malleable to the ever-changing requirements of job sectors such as technology. 2) Accessibility and enablement for the learner to pursue on-demand education and training. 3) Promotion of life- long learning
\end{abstract}

Index Terms - Open badges, open credentialing, open pedagogical frameworks, life-long learning, open standards, skills gap, university-industry co-operation, workforce readiness.

\section{Challenges OF THE SKILls GaP}

Globalization and the rapid evolution of technology have dramatically changed the skills needed by industry in a relatively short amount of time [1]. During this period, educational institutions have been very slow or in some cases even non-responsive - in revising their curriculum to produce students who possess these new and valuable skills. This disconnect has been a major contributor of the current skills gap in the workplace. A skills gap can be defined as the skills that employers need versus skills that is held by workforce [2] Currently, community colleges are the only class of post-secondary institutions that are focused on creating and offering programs targeted primarily on industry needs, often for a defined geographic region [3]. Perhaps the best illustration of the skills gap challenge is that there are now 3.3 million unfilled positions in the United States and roughly half of employers say they are having a hard time finding qualified workers to hire, especially in highly technical fields [4]. Cappelli asserted that the Workforce 2000 report, published by the Hudson Institute in 1986, initiated the United States interest in evolving skill requirements by positing that the transition to higher-skilled jobs would

Manuscript received May 27, 2015; revised January 18, 2016.

Leslie B. Eldridge is with the High5U, United States of America (e-mail: 1.eldridge@high5u.com). outpace the rise of educational levels and create a "skills gap" in the workforce [5].

\section{LINKS IN THE SKILLS GAP SUPPLY CHAIN}

Although determining which entity or actor should shoulder the majority of responsibility for the skills gap is a constant and debatable conversation topic, the reality is that the burden is shared across all major actors in the skills gap supply chain. This includes learners, institutions of higher education, and employers. The access to and availability of knowledge has never been as great as it is in the 21 st century, due primarily to the ubiquitous nature of technology. Maximizing the effectiveness of all links in the skills gap supply chain minimizes some of the challenges, but greater transparency and access to key data across these links is what is necessary to correct some of the larger obstacles.

\section{FUELING THE PROBLEM}

While trying to understand how the dissonance between industry and education occurred, agreeing that there is a great disconnect in perception between both parties is a solid place to start. As an illustration of this perception issue, "Three-quarters (75.6 percent) of employer respondents say that K-12 schools should be responsible for providing the necessary basic knowledge and applied skills for their new entrants. Over two-thirds $(68.4$ percent $)$ say four-year colleges and universities, and (45.2 percent) select two-year colleges among their top three choices. Half of the employer respondents (49.7 percent) say workforce readiness is the responsibility of the new entrants themselves" [6].

Table I reflects the Workforce Readiness Report Card for new entrants into the workforce. Assessment of new workforce entrant readiness on "very important" skills includes basic knowledge and applied skills rated as "very important" by a majority of employer respondents. "Very Important" skills are placed on the Deficiency/Excellence Lists of at least 1 in 5 respondents report entrant readiness as "deficient"/"excellent."

"The Workforce Readiness Report Card for new entrants with a high school diploma has no items on the Excellence List. All 10 skills that a majority of employer respondents rate as "very important" to workforce success for high school graduates are on the Deficiency List of the Report Card. These are: Professionalism/Work Ethic, Teamwork/Collaboration, Oral Communications, Ethics/Social Responsibility, Reading Comprehension, 
English Language (spoken), Critical Thinking/Problem Solving, Information Technology Application, Written Communications, and Diversity. The only applied skill close to being on the Excellence List for new entrants with a high school diploma is Information Technology Application, with fewer than 1 in 6 respondents (15.8 percent)rating skill levels as "excellent."On the Deficiency List of the Workforce Readiness Report Card for new workforce entrants with a high school diploma, the skills include two from the basic knowledge category and ten from among the applied skills. At the top of the Deficiency List is Written Communications, with over 80 percent ( 80.9 percent) of employer respondents reporting that these new entrants' readiness is "deficient" in this "very important" skill. In fact, five of the ten "very important" skills on the Deficiency List are related to communication ability (Written Communications, Oral Communications, Reading Comprehension, English Language (spoken), and Teamwork/Collaboration)" [6].

\section{TABLE I: WORKFORCE READINESS REPORT CARD}

\begin{tabular}{|c|c|c|c|}
\hline Deficiency & $\begin{array}{l}\text { High } \\
\text { School }\end{array}$ & $\begin{array}{l}\text { Two-Year } \\
\text { Colleges }\end{array}$ & $\begin{array}{r}\text { Four-Year } \\
\text { Colleges }\end{array}$ \\
\hline Written Communications & $80.9 \%$ & $47.3 \%$ & $27.8 \%$ \\
\hline $\begin{array}{l}\text { Professionalism/Work } \\
\text { Ethic }\end{array}$ & $70.3 \%$ & -- & -- \\
\hline $\begin{array}{l}\text { Critical } \\
\text { Thinking/Problem } \\
\text { Solving }\end{array}$ & $69.5 \%$ & $22.8 \%$ & -- \\
\hline Oral Communications & $52.7 \%$ & $21.3 \%$ & -- \\
\hline $\begin{array}{l}\text { Ethics/Social } \\
\text { Responsibility }\end{array}$ & $44.1 \%$ & $21.9 \%$ & -- \\
\hline Reading Comprehension & $38.4 \%$ & -- & -- \\
\hline Teamwork/Collaboration & $34.6 \%$ & -- & -- \\
\hline Diversity & $27.9 \%$ & -- & -- \\
\hline $\begin{array}{l}\text { Information Technology } \\
\text { Application }\end{array}$ & $21.5 \%$ & -- & -- \\
\hline English Language & $21.0 \%$ & -- & -- \\
\hline Writing in English & -- & $46.4 \%$ & $26.2 \%$ \\
\hline $\begin{array}{l}\text { Life Long } \\
\text { Learning/Self-Direction }\end{array}$ & -- & $27.9 \%$ & -- \\
\hline Creativity/Innovation & -- & $27.0 \%$ & -- \\
\hline Leadership & -- & -- & $23.8 \%$ \\
\hline Excellence & $\begin{array}{l}\text { High } \\
\text { School }\end{array}$ & $\begin{array}{l}\text { Two - Year } \\
\text { Colleges }\end{array}$ & $\begin{array}{r}\text { Four-Year } \\
\text { Colleges }\end{array}$ \\
\hline $\begin{array}{l}\text { Information Technology } \\
\text { Application }\end{array}$ & --- & $25.7 \%$ & $46.3 \%$ \\
\hline Diversity & -- & -- & $28.3 \%$ \\
\hline $\begin{array}{l}\text { Critical } \\
\text { Thinking/Problem } \\
\text { Solving }\end{array}$ & -- & -- & $27.6 \%$ \\
\hline English Language & -- & -- & $26.2 \%$ \\
\hline
\end{tabular}

The truth and the spectrum of these findings also have an impact on the financial bottom line regarding the skills gap disconnect when trying to retain an employee who is either under-skilled or over qualified. For example, the average cost of a bad hiring decision can equal 30 percent of the individual's first year potential earnings. This means a single bad hire with an annual income of $\$ 50,000$ can equate a potential $\$ 15,000$ loss for the employer [7]. Couple this outcome with the fact that the average tenure of an employee is 4.4 years, and half that if you are a millennial, and we gain a clearer picture of the economic disaster a company endures when the talent pool is drained of resources [8].

In regard to private and public universities, preparing students for jobs that did not exist 25 years ago is nearly impossible to accomplish due to outdated content and traditional education models that are not equipped or open to transparent or digital instruction and industry partnerships. This creates an environment of highly educated graduates but workers with deficient skills. Traditional educational institutions weren't designed for a fast-changing market where skills depreciate quickly and universities weren't designed to change curricula and introduce new classes at the pace required by changing industry requirements [9]. Traditional education has placed a heavy emphasis on measuring what units of knowledge a student possessed while the essence of $21 \mathrm{st}$ century education is based on what students can actually do with their knowledge [10]. Because of emerging technologies and newly created job fields, established workers defined as having skills in the marketplace find themselves needing ongoing training just to maintain minimum industry requirements. Due to the overall complexity of this issue, it becomes imperative that educational models of instruction must change: transparent and open pedagogical frameworks must be implemented so that the relationship between individuals, education, and industry can become a cohesive underpinning to guide eager learners and skill seekers to a successful outcome.

\section{METHODS}

\section{A. Open Solutions: A First Step in Bridging the Skills Gap Supply Chain}

The collaborative efforts of The MacArthur Foundation, HASTAC and Mozilla led to the Open Badges project which first launched in 2011 [11]. Open badges are a simplified way to acknowledge achievements and skills acquired and validated outside of a traditional academic environment.

It is worth distinguishing between the differing concepts of open badges versus digital badges. A digital badge is an online representation of a skill you have earned. Open badges takes that concept one step further and allows you to verify your skills, interests, and achievements through credible organizations and attaches that information to the badge image file, hard-coding the metadata for future access and review. Because the system is based on an open standard, earners can combine multiple badges from different issuers to tell the complete story of their achievements. Badges can be displayed wherever earners want them on the web, and share them for employment, education, or lifelong learning [12].

Applying the concepts and techniques of open solutions such as open badging to education and industry allows a transparent way for all links in the skills gap supply chain to communicate their identity, offerings, and requirements in an interoperable manner.

\section{B. Open Badging and Open Credentialing: What's the Difference?}

Open Badging has been integrated into several top companies such as Disney, NASA, and The Smithsonian Institute, as an integral part of their internal training and professional development offerings [13]. A typical application of Open Badging in this context would involve the 
alignment of content against role-based competency frameworks in tandem with some element of gamification to maximize learner engagement.

Due to its non-traditional approach, the old guard of higher education has been reticent to adopt Open Badging and its related lexicon. The terminology of "Stackable Credentials" and "Open Credentials" is being used more frequently when addressing the concept of Open Badging within higher education given that those terms are more palatable to the relevant stakeholders.

In order to fully enable the potential of open credentialing, the technology behind it needs to produce data points (referred to as open data points for disambiguation from data points collected from any other potential data points) that will direct stakeholders to the likely answers they need. Leveraging the XAPI (formerly known as the Tin Can API), different activities related to a badge participant's learning experience are captured in a collection of statements that are stored in a central LRS (learning record store.) Statements are in the format of <actor (learner) > <verb><object>, with $<$ result $>$, in $<$ context $>$ to track an aspect of a learning experience. (http://tincanapi.com/). These statements accumulate to form a complete snapshot of the learner's experience participating in a specific badge offering or demonstrating a specific skill. This process produces a rich and unique set of data for each learner. Fig. 1 provides an illustration of how this approach works within the context of open credentialing.

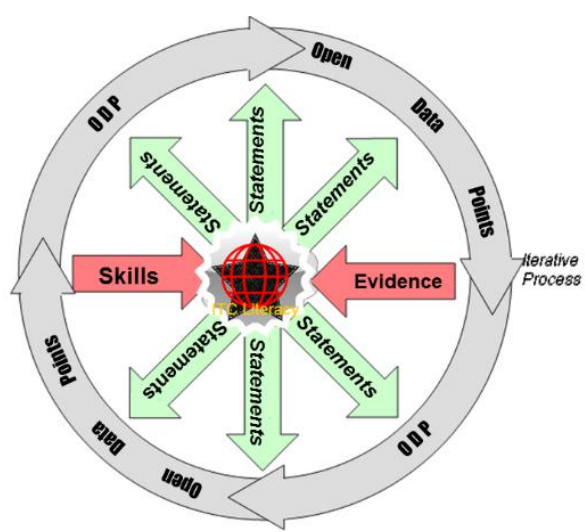

Fig. 1. Generating open data points with the experience API embedded in open credentialing.

A further benefit of this statement driven record approach is that the output of a learner's activity does not need to be translated as they are humanly readable from the moment they are generated. For example, common statements may read "Lisa blogged on leadership" or, "Cameron completed the online component for the leadership 101 badge." Filters can be placed at the LRS level to send out notifications when certain combinations of syntax are present in a statement. These notifications can be sent to badge providers or creators, managers, instructors, parents, or other pieces of content within the broader learning ecosystem.

This flexibility provides open badge providers and participants an almost endless number of permutations for offerings and completion paths for badge achievements [14]. Some examples of strategies afforded by this approach:

- Reuse existing SCORM content as material for a badge program

- Conduct and track group learning experiences such as games and simulations as part of a badge offering

- Queue statements on a mobile device that is offline for later publishing to an LRS

- Create a leader board from a simple report generated from the LRS (great for Millenials)

- Report reading, writing, and commenting on a blog article (several Word Press plug-ins for the Experience API already exist)

- Track the time, modality, location, etc. that the action was completed in

\section{The Application of Open Credentialing and Greater Openness in Higher Education}

More and more, the competiveness of college entrance acceptance, even at the state university level, has elevated the importance of out of classroom activities such as school clubs, social and church-based activities, public service, volunteerism, workplace internships, and other extra-curricular activities. Incorporating open badge recognition as part of the application process greatly streamlines the process and provides a lingua franca to recognize and share achievements outside of the classroom. This approach also provides greater transparency and increased intelligence for high school guidance counselors during the preparation for college entrance applications by assisting in the selection of programs and majors based on a much broader data set than report cards and standardized exam scores.

Extending beyond the application process, higher educational institutions can also offer open credentialing for both traditional topics and supplementary topics such as $21 \mathrm{st}$ century skills, workforce readiness skills, and other areas that are emerging too quickly to offer traditional classroom curriculum.

While these are suggestions to leverage the existing features of open credentialing, higher education could extend the concept of learner based identity to a new open set of descriptions of their own offerings. For example, instead of a badge representing a skill or achievement for an individual, a university could provide a program badge that describe career prospects, number of graduates placed each year, average starting salary, current and future trends, etc. This could greatly influence how relationships with industry are managed and prioritized.

\section{Open Credentialing and their Potential Role in the Workforce}

Open credentialing assists employers by providing additional verified intelligence about potential new hires. This form of credential provides additional information about candidates that otherwise would either be too time consuming or simply impractical to collect using traditional methods. Using open credentialing prevents candidates from falsifying information because each competency earned is authenticated by the third party that hosted the content to receive the credential. The unique feature and benefit of open credentialing is the embedded metadata within badge that allows anyone to view its authenticity. Additional metadata 
information includes curriculum content, competencies, evidence, date awarded, the expiration date where applicable, and the website URL where badging criteria was verified as well as the earner's email address.

Industry can further extend the value of this type of open exchange by publishing job family and role descriptions associated with open positions along with their associated competencies and proficiency levels in a similar manner. This allows job seekers to view skills required for a position and expedite independent decisions to attain those skills. This proactive move by industry provides direct access for both learners and educational entities to help shorten the time to select, on-board, and move new hires to proficiency.

\section{E. Obstacles in Incorporating Digital Stackable Credentials into Closed Frameworks of Education}

When someone who has independently earned a badge attempts to transition this achievement into an academic environment, obstacles such as transcript recognition, accreditation, articulation agreements, and comprehensive PLAs (prior learning assessments) quickly come into play.

These obstacles collectively create a significant roadblock in implementing an open badge or digital stackable credential framework due to the fact that academic institutions are, by their very nature, closed systems and the aforementioned badge and credentialing systems are inherently and purposefully open. Adopting open framework strategies for open badge and digital stackable credentialing approaches that align with existing academic offerings is surely the first major step in removing some of the obstacles that prevent a truly open academic marketplace.

To more closely examine how these obstacles impact individual learners, consider the case of Roberto Alvarez. Roberto lost his job in his late 30's and quickly found himself starting over in the job market. In addition to several Microsoft and A+ certifications, Roberto loves gaming and robotics and earned a badge for completion of the introduction to robotics course at his local technical college. He discovered that he had a proclivity for quickly learning new technology and decided to pursue an academic program in a related field in hopes of advancing his employability. Roberto applied at a university with his existing credentials and was disenchanted by the complexity of the admissions process and disappointed in discovering that none of the robotics or technology skills previously earned transfer as academic credit due to non-recognition as being academically viable.

If a PLA had been in place at the university that aligned to an open framework for emerging technology, Roberto would have been able to gain academic credit and recognition for his prior training and learning achievements as well as his relevant work experience. Without the recognition of these achievements, Roberto, like so many millions of adults reentering the workforce, saw the academic pathway in front of him too daunting and remained either unemployed or underemployed for the next several years due to the lack of academic recognition of skills he clearly had demonstrated mastery in outside of traditional academia.

\section{F. The Importance of Adopting an Open Strategy}

Until now, the learner, industry and educational institutions were given no shared visibility to each other's identity, requirements, and offerings. The learner could only view the programs of the college or university they wanted to attend but had no further perspective around how these programs translated to the workforce. Industry has been myopically focused on expecting job postings to bring in the talent they needed without directly and consistently communicating these requirements to educational institutions. Educational institutions kept a business as usual approach to content and relied on applications of degree programs to sustain them, while learners were under social assumption that earning a college degree equated to a guaranteed career. Without clear visibility across every link in the skills gap supply chain, the individual links cannot operate efficiently and with predictability or clarity. All three of these links have begun to at least initiate the process of investigating the value of an open badging strategy but still need to extend their internal conversations about the value of open credentials to a collaborative conversation. This conversation should take place collectively across all three links, and be focused on creating an even broader open communication and data-sharing framework across all relevant systems and processes.

\section{G. Open Pedagogical Frameworks}

Utilizing an open pedagogical framework will allow open standards between industry and education without losing accreditation requirements on the education side and maintaining the integrity of role based competencies on the industry side. Open standards would create more opportunity for learners and skill seekers who have previously attained credits at other institutions a seamless entrée to fulfill their educational and career objectives. On the industry side, internal training objectives could be aligned to competencies that are also accessible by educational institutions (and vice-versa) so that the skill seeker could use skill training as part of a degree pathway via job training and a learner could take the skill training via education and be equipped to work.

Consider the case of Sara Jones for example: Sara completed an online certificate program in health and nutrition last year while also receiving a digital badge for communication from another organization. Now, Sara wants to construct a plan so she can have her own business to help people who struggle with obesity and be able to interact and communicate with clients and other stakeholders effectively. She has no business or marketing skills to help map out her strategy and has no other post-secondary education. Without the transparency of an open pedagogical framework, it is very unclear to Sara if she should enroll in a university program fulltime, fill in her skill gaps with a combination of open credentials and internships, or pursue a completely different path. Unfortunately, there are many individuals in Sara's predicament. Offering an open pedagogical framework would allow individuals like Sara to view across all possible educational pathways that would lead her to her business and career objectives. This type of utilization of an open pedagogical framework creates a plethora of new opportunities in entrepreneurship, personalization, curation, and ubiquitous learning. 
Open standards are standards made available to the general public and are developed (or approved) and maintained collectively while also driven by the process of consensus. Open standards facilitate interoperability and data exchange among different products or services and are intended for widespread adoption [15]. Adoption of the above definition creates a transparent model between industry and education using open credentialing as a vehicle to bridge the skills gap between the two entities while retaining equity for both. Collaboration between entities would remain voluntary and market driven as well as publicly available with easy implementation and use. Open standards, enabled by technology, facilitate or de-compartmentalizes processes and a traditional silo approach to business. Allowing learners to receive open credentials from educational institutions and open badges from job training on an a la carte basis creates a broader learning and training environment using consumption and demand as a bedrock for development.

\section{CONCLUSIONS AND EXTENSIONS}

Open credentialing is still in its infancy and the development around badge profile standardization, taxonomies, and privacy issues is currently amorphous and broadly undefined. Before open pedagogical frameworks can be put into place, broader sharing of open standard strategies, joint stewardship of XML schema development, and a general desire to collaborate across all links in the skills gap supply chain must be initiated and elaborated upon. Once the proper data architecture is in place, the integration of new and existing tools will be facilitated along with the ability to leverage analytics and big data to help predict industry demand that would help minimize variability concerning the skills gap needs and deficiencies. Communicating this information across individual platforms, educational organizations, and the workforce in a variety of modalities and service levels provides timely access to information that was not previously attainable. With this level of intelligence, government programs and grants could be more targeted toward enabling the goals of all the entities that make up the skills gap supply chain.

As the projects related to this concept continue to form, it is clearer that the core value of this approach is driven by the transparency that it provides across all of the links in the skills gap supply chain, as opposed to the initial perception of the value which was focused more on capturing and predicting the pedagogical inputs and outputs /across the links. This step in the evolution of the framework approach has led to a new overarching concept referred to as Open EYE (Education-You-Enterprise) that places the emphasis on transparency driven by open standards for actor-specific identity standards and definitions across the skills gap supply chain.

\section{REFERENCES}

[1] J. McHale and K. McHale. (2005). Give us your best and brightest: The global hunt for talent and its impact on the developing world. Washington: (Center for Global Development). [Online]. Available: http://international.cgdev.org/sites/default/files/9781933286037-Kap ur-Hale-best-and-brightest.pdf

[2] A. Lesgold, M. J. Feuer, and A. Black, Transitions in Work and Learning: Implications for Assessment, National Academies Press, $\mathrm{p}$ 6, 2007.

[3] T. D. Soneshine. (2013). U.S. Under Secretary of State for Public Diplomacy and Public Affairs. [Online]. Available: http://www.ed.gov/blog/2013/06/community-colleges-a-road-to-build ing-skills-for-the-21st-century/

[4] Jobs Council. (2012). Prepare the American Workforce to Compete in the Global Economy. [Online]. Available: http://files.jobs-council.com/files/2012/01/JC_FactSheet_Education.p df/

[5] P. Cappelli, Change at Work, Library of Congress Cataloging-in-Publication Data (Oxford University Press), 1997, chapter 5, p. 155.

[6] J. Casner-Lotto and L. Barrington, "Are they really ready to work?" Employers Perspectives of the Basic Knowledge and Applied Skills of the New Entrants of the 21st Century U.S. Workforce, 2006, p. 54.

[7] R. Holmes. (2013). The Unexpectedly High Cost of a Bad Hire. [Online]. Available: https://www.linkedin.com/today/post/article/20130716151946-29675 11-the-high-costs-of-a-bad-hire-and-how-to-avoid-them/

[8] J. Meister. (2012). Job hopping is the 'new normal' for millenials Three ways to prevent a human resource nightmare. [Online]. Available:

http://www.forbes.com/sites/jeannemeister/2012/08/14/job-hopping-i s-the-new-normal-for-millennials-three-ways-to-prevent-a-human-res ource-nightmare/

[9] D. Yang. (2013). Can we fix the skills gap? [Online]. Available http://www.forbes.com/sites/groupthink/2013/08/02/can-we-fix-the-s kills-gap/

[10] E. Silva, "Measuring skills for 21 st century learning," Phi Delta Kappa International, vol. 90, no. 9, pp. 630-634, May 2009.

[11] M. Surman. Mozilla launches open badges project. [Online]. Available: https://blog.mozilla.org/blog/2011/09/15/openbadges/

[12] E. Knight et al. (2014). Badges. The Skills Gap: A National Problem That Requires Regional Focus. [Online]. Available: https://wiki.mozilla.org/Badges.

[13] (2015). Mozilla open badges. Participating Issuers. [Online]. Available: http://openbadges.org/participating-issuers/

[14] L. Eldridge, "Open badges, big data \& analytics: A curative approach integrating 21st century skills into the modern workforce," ICERI2014 Proceedings, pp. 4503-4510, 2014.

[15] International Telecommunications Union (ITU). (2005). Definition of open standards. Intellectual Property Rights Ad Hoc Group (IPR). [Online]. Available: http://www.itu.int/en/ITU-T/ipr/Pages/open.aspx

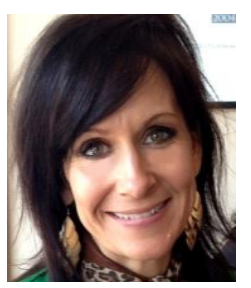

Leslie Eldridge was born and raised in Kentucky. The primary concentration of her academic studies was in holistic health. Leslie is a 2013 graduate of the Institute for Integrative Nutrition (IIN) in New York City, New York where she earned a certificate in Integrative Holistic Health.

She has worked extensively in leadership and management positions within private and public sector organizations including tenures in the coal industry and inside local government agencies. She is currently International Business Manager for eCom-USA in Athens, Georgia. Leslie is very engaged in the open badging and open credentialing community where she serves on the working group for badges in higher education and digital literacy. She is very passionate about the learning and educational industry at large and is actively working on new and innovative ways of closing the skills gap with emerging technologies and avant-garde pedagogical techniques. 